\title{
NovosCadernos NAEA
}

v. 9 , n. 1, p. 119-130, jun. 2006, ISSN 1516-6481

\section{Caboclos na Amazônia: a identidade na diferença*}

Carmen Izabel Rodrigues - Professora Associada ao Departamento de Antropologia da Universidade Federal do Pará

\section{Resumo}

Neste trabalho propomos discutir algumas questões relacionadas às essencializações e reificações presentes nos processos de construção de identidades e reivindicações de diferenças culturais no mundo contemporâneo, com destaque à questão da identidade (ou não-identidade) do caboclo amazônico. Podemos falar em identidade cabocla? Se caboclo não é uma categoria étnica, no sentido estrito do termo, é no jogo da diferença que ele é construído, assim como outros sujeitos/objetos antropológicos.

\begin{abstract}
This work aims at discussing issues related to essentialness and reification, which are found in identity construction processes, as well as in current worldwide cultural differences claims, particularly the identity (or non-identity) of the Amazonian caboclo. Can we talk about a caboclo identity? If caboclo is not an ethnic category, in the strict sense of the term, then it is in the game of difference that it is constructed, as well as other anthropologic subjects/objects.
\end{abstract}

\section{Palavras-chave}

Essência, identidade, Caboclo, Amazônia

\section{Keywords}

Essence, Identity, Mestizo, Amazonian

\footnotetext{
* Artigo apresentado no Curso de Divisões Sociais, PPGS/UFPE, 2002. É também parte da Conclusão da Tese de Doutorado em Antropologia intitulada "Vem do bairro do Jurunas: sociabilidade e construção de identidades entre ribeirinhos em Belém-PA". PPGA/UFPE, 2006.
} 
Carmen laabel Rodrigues

\begin{abstract}
"Vou contar a minha história, mas por viagens. Montado a cavalo, eu sempre esbarrava em margens e barrancos. Já quando me avezei pela canoa gita, desapareceu pra mim essa questão de margens e ribanceiras cortantes. Os furos, os igarapés, os rios e os lagos me davam a impressão de ser sempre uma pessoa refletida num espelho andante e baita. Pra mim, paresque, era a linha d'água que dividia o mundo (...) Comecei também a chegar nas cidades por pontes e trapiches. Tudo passou a ser marcado por chegadas e saídas. Por isso agora só conto a minha vida por viagens. Ela passou a ser assim, sem paradeiro certo, dependendo da maré das águas, das pessoas e até dos objetos. O senhor pensa que regatão tem algum destino? Só tem chegadas e saídas. Por isso também que agora conto a minha vida por paradas. Aliás, foi nas paradas que consegui arrumar a minha descendência..." (Benedicto Monteiro, 1991: 31-34).
\end{abstract}

Neste trabalho propomos discutir algumas questões relacionadas às essencializações e reificações presentes nos processos de construção de identidades e reivindicação de diferenças culturais no mundo contemporâneo, com destaque à questão da identidade (ou nãoidentidade) do caboclo amazônico. O debate atual acerca da fabricação de identidades no mundo contemporâneo pode ser resumido em três aspectos principais:

a) as construções das identidades (modernas ou pós-modernas), tal como reveladas pelas análises sociais, apontam um paradoxo: enquanto os analistas sociais reconhecem que as identidades não são categorias ontológicas, essenciais ou primordiais, os grupos promovem, cada vez mais, a essencialização e a reificação das identidades, apresentando-as como fixas, primordiais, promovendo o retorno à etnia e exigindo o direito à diferença.

b) essa essencialização da diferença articula-se de diversas maneiras com os projetos políticos apresentados pelos grupos em processos de "negociação e afirmação da identidade" (Bauman, 2001), ora a favor do acesso irrestrito aos direitos humanos universais, ora a favor do respeito às especificidades culturais.

c) sendo múltiplas e flexíveis, essas identidades podem ser apropriadas ou descartadas, vestidas ou despidas, em um processo incessante de construção, criação e inovação (Agier, 2001), articulam-se dentro e através de fronteiras étnicas (Barth, 2000), ultrapassando os limites políticos, sociais e culturais. 
Segundo Pierucci (1999), diferenças coletivas são marcadas através de traços distintivos, reais ou inventados, herdados ou adquiridos, genéticos ou ambientais, naturais ou construídos, por grupos de pertencimento ao longo de linhas demarcatórias de raça, etnia, procedência, sexo e gênero, idade, nacionalidade ou região. Essas linhas demarcatórias definem inclusão ou exclusão, superioridade ou inferioridade de um grupo em relação aos outros, com base em marcas ou atributos empíricos, sensíveis, muitas vezes visíveis, de diferenças tornadas significativas através de práticas sociais operadas cotidianamente por grupos que ora enfatizam, ora ignoram ou obscurecem essas diferenças, negando sua influência ou determinação na conduta, no caráter, no sucesso ou no fracasso de cada indivíduo, de modo que enfatizar as diferenças, tanto quanto ignorá-las e tratar igualmente os diferentes, pode estigmatizar pessoas e grupos, barrando ou limitando seu acesso às oportunidades na sociedade mais ampla (:104-6).

Como vimos, reificações da diferença e essencializações da identidade podem estar presentes nos diversos processos de constituição dos grupos étnicos. Entretanto, "reificações ou essencializações da etnia, assim como reificações que envolvem gênero ou identidade nacional, não são boas do ponto de vista político" (Moreiras, 2001: 313). Partindo dessas considerações, trataremos aqui de uma categoria social de difícil categorização, de um objeto difícil de ser objetificado - a identidade (ou não-identidade) do caboclo amazônico.

Se tomarmos a conhecida noção de grupo étnico elaborada por Barth (2000), na qual a auto-atribuição e a atribuição pelos outros é sua característica principal, temos duas questões iniciais:

a) as duas condições são indispensáveis e concomitantes, isto é, não podem faltar e têm que estar presentes ao mesmo tempo?

b) as duas condições têm que se apresentar nessa ordem? ou seja: uma fronteira étnica é demarcada quando um grupo étnico afirma sua especificidade e exige seu direito à diferença, à especificidade de grupo minoritário que deseja ser reconhecido enquanto tal?

No caso específico da categoria caboclo, uma categoria de atribuição pelos outros e não de auto-atribuição, uma categoria de acusação e não de reconhecimento de direitos e prerrogativas, podemos afirmar que a identidade caboclo existe? Como um tema constante na literatura regional, sua presença no debate atual sobre a identidade amazônica, seja em trabalhos acadêmicos, seja em artigos jornalísticos, é marcada por ausências, por uma espécie de invisibilidade que mais nega que afirma, e que nos aponta a fantasmagoria de uma categoria. Como dar conta dessa fantasmagoria? 
Carmen lzabel Rodrigues

Em primeiro lugar, o caboclo é uma categoria de alteridade, que fala sempre de um outro. Em segundo lugar, não é um ser ou uma essência, mas uma categoria de representação. Lima-Ayres (1999) refere-se a duas concepções gerais acerca do caboclo amazônico: no sentido coloquial "o termo caboclo é amplamente utilizado na Amazônia brasileira como uma categoria de classificação social"; nesse sentido:

\begin{abstract}
"a categoria caboclo é complexa, ambígua e está associada a um estereótipo negativo; no uso acadêmico, refere-se aos pequenos produtores rurais de ocupação histórica, também classificados como camponeses (...) no sentido coloquial, o caboclo é uma categoria de classificação social complexa que inclui dimensões geográficas, raciais e de classe (...) na região amazônica o termo é também empregado como categoria relacional; o termo identifica uma categoria de pessoas que se encontra em uma posição social inferior em relação ao locutor (...) os parâmetros desta classificação coloquial incluem a qualidade rural, descendência indígena e "não civilizada" (analfabeta e rústica) que contrastam com as qualidades urbana, branca, civilizada (...) Como categoria relacional, não há um grupo fixo identificado como caboclo; o termo pode ser aplicado a qualquer grupo social ou pessoa considerada mais rural, indígena ou rústica. O uso coloquial do termo leva à suposição de que existe uma população concreta que pode ser imediatamente identificada como cabocla e carrega a identidade de caboclo" (:5-7)
\end{abstract}

Percebemos, na análise da autora, a dificuldade de se chegar a uma única definição ou sentido do termo caboclo: ora o termo aparece como uma representação, uma categoria de atribuição pelos outros (brancos, não-caboclos), ora o termo torna-se mais "empírico" e "fixo", referindo-se a pequenos produtores familiares da Amazônia. Entre os diversos significados atribuídos ao termo, predomina um sentido pejorativo, negativo, que define caboclo como

"o indivíduo ou grupo que ocupa uma posição social inferior. Embora haja também uma valorização positiva - no folclore (homem da terra) e em cultos de possessão em que aparece como "espírito forte" (Boyer, 1999) - o estereótipo predominante é negativo; corresponde a figuras como matuto e caipira do interior sulista (...) Não há uma identidade clara, forte e socialmente valorizada relacionada ao termo; internamente, o indivíduo constrói sua noção de pessoa com outros referenciais, ligados à condição social (pobre), à principal atividade econômica (pesca artesanal, agricultura 
de pequeno porte, coleta de castanha), ao ambiente que ocupa (várzea ou terra firme), aos laços de parentesco locais (comunidades de parentes), à cosmologia e à religião que professa (mundo dos encantados, catolicismo popular ou seitas pentecostais)" (Lima-Ayres, 1999: 26).

Segundo Lima-Ayres "o termo caboclo, no discurso coloquial, não se refere a um grupo social nem corresponde a um grupo étnico" (1999: 21) nos termos de Barth (2000); de modo geral, os habitantes rurais da Amazônia definem-se como agricultores; também nunca foi associado a um movimento político (Lima-Ayres, 1999: 22); por isso devemos "desistir do uso da palavra caboclo, especialmente se pretendemos falar de identidades rurais na Amazônia contemporânea", posto que a identidade cabocla não existe de fato, "é uma representação" (:29); não há uma afirmação de ser caboclo mas sim uma aceitação contextual do rótulo, no sentido de uma "identidade negativa" (Cardoso de Oliveira, 1972); o caboclo é aquele que não é... é a aceitação da negação".

Entretanto, partindo da análise do fenômeno do caboclismo entre os tükuna no Alto Solimões como "formas de ser do caboclo"e, ao mesmo tempo, "a própria negação do tükuna transfigurado pelo contato com o branco" (Cardoso de Oliveira, 1972: 104), podemos pensar esse fenômeno como uma recusa do termo em função de seu sentido pejorativo no contexto onde é produzido, mas também como uma afirmação de que não fazem parte da categoria maior, "branca" que os rotula e discrimina.

A categoria caboclo torna-se, assim, um problema teórico e ético, tanto quanto político: uma identidade reificada pela negação, como alguém ou algo que esta fora do lugar (da modernidade contemporânea); ao mesmo tempo, é aquele que não tem consciência de si, ou pior, é aquele que pensa pelas representações e estereótipos construídos pelos outros (Cardoso de Oliveira, 1976), ou mesmo através de uma "dupla consciência" (Gilroy, 2001).

Saillant e Forline (2001) destacam o caráter de exterioridade do conceito, como um reflexo das forças externas que se impuseram na região amazônica (:146), tal como analisado por Nugent (1993). Num contexto de modernidade globalizadora, o caboclo estaria "entre a floresta, a indianidade e suas franjas" (:146), ao mesmo tempo "testemunha e sujeito de uma memória e identidade residual ...sempre... em movimento" (146). Não possuindo os atributos positivos das categorias que o construíram, seria o inverso da identidade nacional, ou seja, aquele que não conseguiu se integrar à sociedade brasileira, ao mesmo tempo 
em que procurou apagar os traços dessa (não)identidade. Daí sua propalada invisibilidade, sua falta de memória, sua história silenciada e sua ausência nas instâncias políticas e sociais mais amplas.

Por outro lado, nos discursos atuais em defesa da riqueza e da biodiversidade amazônica, o caboclo é visto como o guardião da floresta, aquele que detém os saberes nativos sobre a região. Neste contexto o caboclo é reconstituído como originário do lugar, herdeiro dos antepassados indígenas e totalmente adaptado à natureza (Saillant e Forline, 2001: 148-49).

Boyer (1999), referindo-se à multiplicidade de sentidos da palavra caboclo, enfatiza que na cidade de Belém o termo não se refere a um conteúdo étnico. ${ }^{3}$ O termo aplica-se então ao habitante interiorano da Amazônia, tal como referido por Alves (1993), para quem o termo caboclo é uma designação nativa (:170), uma categoria tradicional para designar o habitante da região (:174), especialmente o morador do interior (:167). Como categoria de referência regional, em oposição aos que são de fora, torna-se uma "instância de resistência (...) a outros modos de concepção [inclusive] das diferenças sociais" (:175).

Nas diversas tentativas de reconstrução positivada da identidade dos habitantes da Amazônia, outros termos foram apropriados e legitimados: ribeirinhos (Miller, 1977; Chibnik, 1994; Harris, 2004), povos da floresta (Wolff, 1999), povos tradicionais. Wolff (1999), estudando a vida das mulheres da floresta no alto Juruá, encontrou um uso comum do termo caboclo na região, para "designar índios em geral (...) acompanhado dos adjetivos brabo ou manso, dependendo se são índios civilizados ou selvagens [e usado] para classificar indivíduos ou famílias de ascendência indígena que vivem nos seringais". (184). Seguindo Wagley (1977) a autora concorda que o termo serve principalmente para expressar uma relação social.

O termo ribeirinho, hoje usado amplamente pela mídia local para falar das populações amazônicas, não aparece na literatura antropológica antes dos anos setenta, quando Miller (1977) refere-se às "comunidades ribeirinhas tradicionais", pequenas cidades localizadas ao longo do rio

\footnotetext{
${ }^{3}$ "Abandonando o sentido de índio ou de mestiço de índio e branco, caboclo, para a população atual da cidade, designa geralmente o habitante do meio rural, qualquer que seja a sua origem (...) o uso do termo tem forte carga negativa" (Boyer, 1999: 30).

${ }^{4}$ "De maneira geral (...) caboclo serve tanto para designar genericamente os índios como para marcar hierarquias sociais (...) A palavra. (...) carrega ainda um sentido relacional, pois se opõe a outra categoria: cearenses ou "carius"(...) é necessário atentar para o caráter hierárquico da oposição "caboclo/cearense", pois os caboclos são sempre apontados com qualidades negativas, mesmo pelos próprios descendentes... (Wolff, 1999: 187,190).
} 
Amazonas, não muito próximas aos centros mais desenvolvidos, ainda não alcançadas pela malha rodoviária, e ignoradas pelos projetos desenvolvimentistas aplicados à região (:285).

Harris (2004) refere-se às pequenas povoações de várzea no médiobaixo Amazonas,

\begin{abstract}
"agrupadas em redes de parentes por cerca de $30 \mathrm{~km}$ ao longo do rio (...) vivendo de atividades econômicas sazonais (...) não apenas na margem de um grande rio, como sobre o rio - e algumas vezes dentro dele - por vários meses durante o ano (...) Seus residentes são chamados ribeirinhos, um termo que expressa uma associação geográfica e não uma identidade étnica" (:4).
\end{abstract}

Chibnik (1994) estudou populações amazônicas vivendo em pequenas comunidades ribeirinhas (riverine villages) próximas a Iquitos (:74) e verificou que "a auto-identidade dos residentes nas aldeias ribeirinhas envolve mistura de descendência, feições culturais, distinções de classe, categorias ocupacionais e regionalidade" (:82). Destacando, a partir de Cohen (1978), a existência de uma aura da descendência nas concepções de um grupo étnico, de modo que, "uma vez adquiridas as identidades étnicas por qualquer processo, são passadas de geração a geração" (Chibnik, 1994: 82), e identificando a presença de fronteiras quase-étnicas entre não-ameríndios nascidos no local e outros grupos, o autor conceitua os ribeirinhos amazônidas como quase-grupos étnicos e conclui que "uma teoria antropológica da etnicidade" permitirá entender "os modos pelos quais os ribeirinhos se distinguem de outros peruanos" (:82).

Voltamos aqui a uma questão central na definição de um grupo étnico: a afirmação da identidade através do estabelecimento de fronteiras simbolicamente construídas, baseadas em diferenças culturais, muitas vezes naturalizadas pelos sujeitos, mas sempre usadas como definidoras de seu pertencimento a um grupo, região, nação, etc.

Entretanto, a questão mais importante a ser considerada na análise da categoria caboclo é exatamente a da não-definição: o caboclo é aquele que está nas franjas, nas fronteiras da modernidade, o que estava antes da modernidade, o que é, de certo modo, contra a modernidade. No

\footnotetext{
${ }^{5}$ "Ribeirinhos são ditos misturados de europeus e ameríndios (...) alguns têm sobrenomes espanhóis, outros têm nomes típicos de grupos ameríndios (...) muitas populações rurais têm pais ou avós que falam línguas indígenas [e] a maioria delas abertamente desdenha o [termo] ameríndio e se auto-identifica como ribeirinhos... (Chibnik, 1994: xii; tradução livre).
} 
Carmen labbel Rodrigues

jogo do dentro e fora, do interior/exterior (Bhabha, 1998), o caboclo está no meio da modernidade, nas margens e - ao mesmo tempo - fora dela.

Como lidar com esses movimentos e margens usando as categorias domesticadas através das quais delimitamos nosso conhecimento da realidade? Analisando a questão nos termos de Bhabha (1998) sobre as identidades situadas nos interstícios da cultura (:19), e para quem a diferença cultural, moldada historicamente no sistema colonial, construída politicamente na oposição ocidente/oriente, extrapola, extravasa suas fronteiras, impondo e expondo a condição liminar do migrante que "transforma-se no fantasma do colonizado que vem assombrar o colonizador" (:59, 211), podemos pensar a categoria caboclo como a fantasmagoria que assombra o amazônida urbano, cosmopolita, moderno, (em muitos casos ex-migrante, ex-caboclo).

Podemos também pensar essa categoria como um lugar de representação, ao mesmo tempo um lugar residual e uma fronteira móvel, que avança e recua. Uma cultura cabocla, vista sempre como um lugar residual, não existiria como cultura própria; afirmar-se-ia pela negação; seria então um espaço marcado por um duplo discurso de exclusão: de quem olha e fala do exterior, o caboclo é aquele que está fora da modernidade. De quem olha do interior, e vê o outro como espelho - ao mesmo tempo em que se vê pelos olhos do outro - o caboclo é aquele que deseja ser o outro de si mesmo. ${ }^{6}$

Demonstrando corretamente que a rotulação do caboclo amazônico é um exemplo emblemático do poder de nomear (Bourdieu, 1989, 1998), que é ao mesmo tempo "uma forma de expressar a dominação de uma classe sobre outra", Lima-Ayres (1999: 27), afirma que "manter o uso da palavra caboclo demonstra que desconhecemos as formas como eles próprios se apresentam / representam; nesse sentido, o nome caboclo vive hoje apenas no discurso que nós fazemos sobre uma outra categoria social" (1999: 29).

Concordamos com a autora no sentido de que a identidade cabocla é uma representação, na medida em que as identidades são sempre representações, construções, narrativas discursivas através das quais

\footnotetext{
${ }^{6}$ Segundo Motta-Maués (1989) "as idéias e imagens do que se convencionou chamar de 'homem amazônico' (...) construídas ao longo da história da região, continuam a ser veiculadas ainda hoje, compondo a forma de pensar e falar sobre ele, como constituindo sempre um "outro" com quem não se quer ser confundido (...) Ninguém quer ser identificado com o caboclo ou com as 'coisas de caboclo' - a chamada caboclice - todos termos pejorativos e eivados de preconceito que se dirigem, no fundo, contra a velha realidade que não se quer encarar de frente - o fato de ser esta, na verdade, uma população misturada" (:195, 203)
} 
os sujeitos (ou não-sujeitos) são rotulados, mas discordamos da mesma no sentido de que matar o caboclo enquanto conceito / categoria seria fingir que não existe uma diferença que se construiu historicamente, que se instalou de fora para dentro, do nacional para o local, e que se desdobra continuamente, contra, entre, dentro do espaço-tempo amazônico, com relação a seus diversos grupos populacionais pensados, nesse contexto, como primordiais e, portanto, essencializados, como uma raça de cultura mestiça e costumes atávicos; resistentes à modernidade, verdadeiros exemplos da contra-modernidade que ainda sobrevivem no mundo ocidental.

É nesses limites e fronteiras conceituais, políticas e éticas, que se abre o espaço para se pensar a questão do caboclo como uma identidade e cultura de resistência, posto que são sobreviventes de um processo aniquilador, mas que não os destruiu por inteiro. Abre-se então o espaço da terceira margem (Monteiro, 1991); da fala dos sobreviventes que estão entre as culturas, no meio da modernidade (Bhabha, 1999). Finalmente, aqui se pode abrir o espaço de construção de novos sujeitos, nos entrelugares onde a diferença se faz e se refaz incessantemente.

Um aspecto aparentemente insignificante pode ser relevante para se pensar acerca da produção da consciência e da posicionalidade dos sujeitos (Bhabha, 1998; Anthias, 1998) rotulados como caboclos, nos seus próprios termos e contextos: a acusação jocosa que os indivíduos ou grupos de ribeirinhos se fazem entre si, rotulando-se mutuamente ou auto-rotulando-se de caboclos, ${ }^{7}$ utilizando-se de tempos verbais passados, presentes e futuros para referir-se àqueles que já foram, àqueles que ainda são, àqueles que não mais serão caboclos.

Fixar a atenção nesse processo específico de desdobramento da diferença, no sentido/direção da acusação/nomeação, através dessa fronteira portátil (Lask, na Introdução a Barth, 2000) que é a identidade cabocla na Amazônia; observar o lugar/posição de quem nomeia, para perceber o olhar de cima para baixo (Wagley, 1977) é o caminho que pode nos permitir desvendar alguns mecanismos desse processo de rotulação do caboclo; afinal, quem nomeia não quer ser chamado de caboclo; acusa para não ser acusado, rotula para não ser rotulado. Nesses desdobramentos, fixar também a atenção nos aspectos de ambigüidade presentes na identidade caboclo, como aquele que recusa a modernidade

\footnotetext{
7 "Colera não mata caboclo". Segundo Mark Harris (2000: 29) essa declaração é um exemplo de auto-afirmação, feita por um pescador na cidade de Óbidos, no Pará, para distinguir-se, enquanto caboclo - que realiza seu trabalho e garante sua sobrevivência através de atividades e comportamentos adaptados à região -, dos diversos outros: os ricos, a gente fina (que não trabalha pela sobrevivência) e, inclusive, o antropólogo.
} 
e, ao mesmo tempo, está sempre pronto a adotar/copiar o novo.

Portanto, a categoria caboclo não é apenas uma categoria relacional, mas antes de tudo, intersticial, intervalar, categoria mediadora entre o dentro e o fora, o interior e o exterior, e não pode ser apreendida em termos de descontinuidades e rupturas, conceituais ou práticas, entre um espaço regional e um tempo colonial, e os espaços e tempos póscoloniais, translocais ou transnacionais. Mas, ainda que, conceitualmente, imprecisa e politicamente não-situada, deslocada entre fronteiras e margens, exatamente por isso pode permitir melhor o exercício de auto-reflexividade sobre o contexto amazônico e a constituição de seus sujeitos.

Diante do que foi exposto, podemos falar em identidade cabocla? Se o caboclo não é uma categoria étnica, no sentido estrito do termo, é no jogo da diferença que ele é constituído, assim como outros sujeitos/ objetos antropológicos. Como uma diferença, a identidade cabocla é uma fronteira sempre em movimento - de expansão ou retração -, nunca igual a si mesma, sempre em transformação. Nesse movimento, na busca de "tornar-se outro", é que se abre um espaço de reflexividade: ao dar significados à sua experiência de margens e movimentos, o caboclo pode, enfim, auto-constituir-se como uma fala, ao mesmo tempo heterogênea e autônoma, local e nacional, singular e plural. Afinal, "não há melhor discurso sobre a identidade do que aquele que se enraíza na incessante (e inevitável) transformação" (Polar, 2000: 304). 
Caboclos na Amazônia: a identidade na diferenç̧a

\section{REFERÊNCIAS BIBLIOGRÁFICAS}

AGIER, Michel . Distúrbios identitários em tempos de globalização. In: MANA, vol 7, n 2, 2001.

ALVES, Isidoro. Promessa é dívida... valor, tempo e intercâmbio ritual em sistemas tradicionais na Amazônia. Museu Nacional, PPGAS (T. Doutorado), 1993.

ANTHIAS, Floya. Rethinking Social Divisions: some notes towards a theoretical framework. In: Sociological Review. Volume 46, Number 3, 1998.

BARTH, Fredrik. Os grupos étnicos e suas fronteiras. In: $O$ guru, o iniciador e outras variações antropológicas. Org. Tomke Lask. Rio de Janeiro: Contracapa. [1969], 2000.

BAUMAN, Zigmunt. Identity in the globalising world. In: Social Anthropology. EASA, vol 9, part 2, 2001.

BHABHA, Homi. O local da cultura. Belo Horizonte: Editora UFMG, 1998.

BOURDIEU, Pierre. A economia das trocas lingüísticas. São Paulo: Edusp. 1998.

O poder simbólico. Lisboa: Difel, 1989.

BOYER, Véronique. O pajé e o caboclo: de homem a entidade. MANA, 5 (1), (:29-56), 1999.

CARDOSO DE OLIVEIRA, Roberto. Identidade, Etnia e Estrutura Social. São Paulo: Editora Pioneira, 1976.

O Índio e o Mundo dos Brancos. São Paulo: Pioneira. 1972.

CHIBNIK, Michael. Risky Rivers. Tucson: University of Arizona Press. 1994.

GILROY, Paul. O Atlântico Negro. São Paulo: Editora 34. 2001 .

HARRIS, Marc. Life on the Amazon. Oxford: Oxford University Press. 2000 . 
Carmen lzabel Rodrigues

Santos, Encantados e Panema numa Comunidade Amazônica

(mimeo). 2004.

LIMA-AYRES, Déborah. A construção histórica da categoria caboclo. Sobre estruturas e representações sociais no meio rural. In: Novos Cadernos NAEA, vol 2, no 2, UFPA. 1999.

MILLER, Darrel. Itá em 1974: um epílogo. In: Charles Wagley: Uma comunidade amazônica. São Paulo: Editora Nacional, 2a edição. 1977.

MONTEIRO, Benedicto. A Terceira Margem. Belém: Cejup, 3a edição. 1991.

MOREIRAS, Alberto. A exaustão da diferença. Belo Horizonte: Editora UFMG. 2001.

MOTTA-MAUÉS, Maria Angélica. A questão étnica: índios, brancos, negros e caboclos. In: Estudos e problemas amazônicos. Belém: Idesp/Seduc (196-204). 1989.

NUGENT, Stephen . The Amazonian caboclo society. Providence/Oxford: Berg Publishers. 1993.

PIERUCCI, Antônio Flávio. Ciladas da Diferença. São Paulo: Editora 34. 1999.

POLAR, Antonio Cornejo. O Condor Voa. Literatura e cultura latinoAmericanas. Belo Horizonte: editora UFMG. 2000 .

SAILLANT, Francine e FORLINE, Louis. Memória fugitiva, identidade flexível: Caboclos na Amazônia. IN: Devorando o tempo: Brasil, país sem memória. A. Leibing e S. Benninghoff-Lühl (orgs). São Paulo: Mandarim (:143-156). 2001.

WAGLEY, Charles. Uma comunidade amazônica: estudo do homem nos trópicos. São Paulo: Editora Nacional. 1977.

WOLFF, Cristina Scheibe. Mulheres da Floresta: uma história. Alto Juruá, Acre. São Paulo: Hucitec. 1999.

Texto submetido à Revista em 09.01.2006 e aceito para publicação em 22.05.2006.

130 